\title{
Forecasting the Oil Volatility Index Using Factors of Uncertainty
}

\section{Panagiotis Delis ${ }^{1}$ \\ Stavros Degiannakis ${ }^{1,2}$ (D) Konstantinos Giannopoulos ${ }^{1}$}

'Panteion University of Social and Political Sciences, Department of Economic and Regional Development, Athens, Greece.

${ }^{2}$ Bank of Greece, Athens, Greece.

'Email:p.delis@panteion.gr Tel: 00302710227993

1.2Email: s.degiannakis@panteion.gr Tel:0030 2109230916

'Email: kwestasgiannopoulos@yahoo.gr Tel:00306980476424.

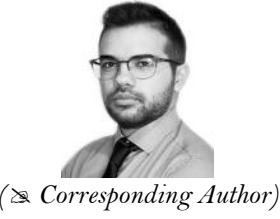

Corresponding Author

\section{Abstract}

The oil volatility index (OVX) has attracted the attention of investors, as oil prices have been subject to high degrees of variation in the last few decades, and investors would therefore benefit from obtaining accurate forecasts of OVX. In this paper, we aim to develop models that can accurately generate OVX forecasts. The contribution of our study to the literature lies in the incorporation of different factors that reflect uncertainty as potential drivers of OVX. For example, implied volatility (IV) indices, such as the VIX and GVZ are examined. Apart from the inclusion of IV indices, we investigate whether other uncertainty indicators play a significant role in generating OVX forecasts. Our results show that the predictive ability of the models is not enhanced by the inclusion of most of the aforementioned factors of uncertainty, with the single exception of the U.S. economic policy uncertainty index, which seems to improve the forecasting ability of a simple model that focuses on the OVX as a target variable.

Keywords: Volatility forecasting, Crude oil, Implied volatility, Uncertainty, Out-of-sample forecasting, Statistical loss functions. JEL Classification: C10, G15, Q47.

Citation | Panagiotis Delis; Stavros Degiannakis; Konstantinos Giannopoulos (2022). Forecasting the Oil Volatility Index Using Factors of Uncertainty. Asian Journal of Economics and Empirical Research, 9(1): 13-20.

History:

Received: 29 November 2021

Revised: 4 January 2022

Accepted: 17 January 2022

Published: 25 January 2022

Licensed: This work is licensed under a Creative Commons Attribution 3.0 License $(\mathrm{cc})$ E

Publisher: Asian Online Journal Publishing Group
Funding: This research is co-financed by Greece and the European Union (European Social Fund- ESF) through the Operational Programme of Human Resources Development, Education and Lifelong Learning 2014-2020 (grant number, MIS-5049106).

Authors' Contributions: All authors contributed to the conception and design of the study.

Competing Interests: The authors declare that they have no conflict of interests.

Transparency: The authors confirm that the manuscript is an honest, accurate, and transparent account of the study was reported; that no vital features of the study have been omitted; and that any discrepancies from the study as planned have been explained.

Ethical: This study follows all ethical practices during writing.

\section{Contents}

1. Introduction

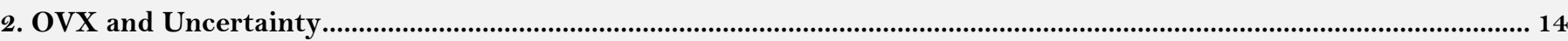

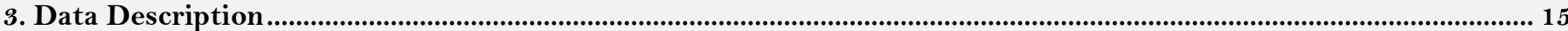

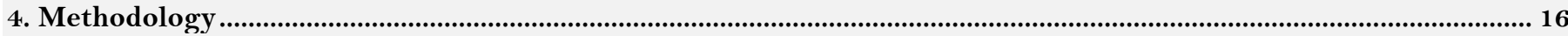

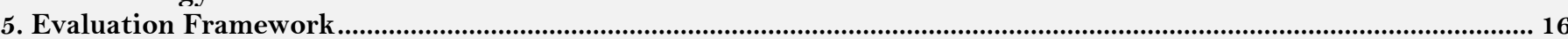

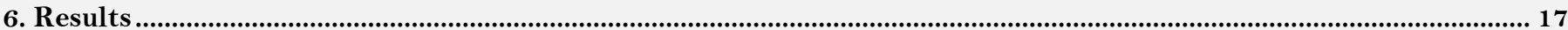

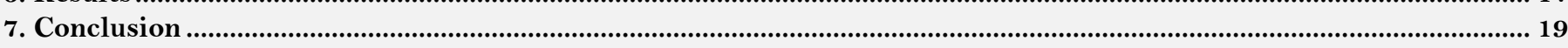

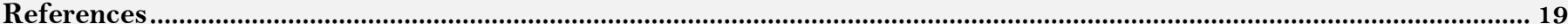




\section{Contribution of this paper to the literature}

This study contributes to the existing literature by investigating the predictive performance of models that incorporate several factors of uncertainty, including implied volatility indices and other indicators that capture uncertainty, on the oil implied volatility index (OVX). Moreover, the study focuses on generating OVX forecasts in an out-of-sample analysis.

\section{Introduction}

Oil prices are experiencing a period of high volatility, which is of major importance to the global economy. Oil price volatility can arise from either supply or demand shocks, which in turn are triggered by different factors of uncertainty. Since oil price volatility is a measure that shows the level of change that oil prices undergo, investors are interested in predicting it. According to prior research (Blair, Poon, \& Taylor, 2001; Frijns, Tallau, \& TouraniRad, 2010; Giot, 2003) implied volatility (IV) indices provide increased predictive information when generating volatility forecasts. Therefore, this study focuses on the oil volatility index (OVX) as a measure of oil price volatility, which is constructed by CBOE using the implied volatility methodology. ${ }^{1}$ A small number of previous studies has focused on OVX predictability and the investigation of the variables that can improve the forecasting ability of the models used to generate OVX forecasts. For example, Mazzeu, Veiga, and Mariti (2019) found that including the leverage in the conditional mean or variance of the basic Heterogeneous Autoregressive (HAR) model increases its predictive ability. However, they did not include exogenous information in their efforts to improve the forecasting performance of the simple HAR model. The literature includes papers that focus on generating forecasts for other IV indices, rather than OVX. For example, Degiannakis (2008) provided an empirical model that produced one-dayahead predictions of the VIX index and found that the intraday volatility measure did not yield significant incremental forecasting information on VIX. Konstantinidi, Skiadopoulos, and Tzagkaraki (2008) implemented six alternative model specifications, including models featuring economic variables as exogenous information, to generate forecasts for a number of European and U.S. IV indices. Moreover, Degiannakis, Filis, and Hassani (2018) applied parametric and non-parametric techniques in order to forecast implied volatility indices, such as the VIX. In addition, the work of Dunis, Kellard, and Snaith (2013) focused on forecasting the EUR-USD IV index. In this paper, we study two different clusters of uncertainty, which each consist of indicators that may offer predictive information on OVX. The first cluster includes three IV indices that correspond to the main markets, namely the stock and commodity (gold) markets and the market reflecting the macroeconomic conditions. The second cluster includes indicators that can be of major importance for predicting uncertainty in the U.S. markets. The first variable in this cluster is the U.S. economic policy uncertainty (EPU) index, which is based on newspaper archives and focuses on three main areas, namely the economy, the uncertainty, and the legislation or regulation. The second, namely the geopolitical risk (GPR) index, captures adverse geopolitical events by using newspaper articles covering geopolitical tensions. Finally, a representative measure of the real business conditions is offered by the index constructed by Aruoba-Diebold-Scotti (ADS), which captures information from several economic indicators, such as weekly initial jobless claims, monthly industrial production and quarterly real GDP. The advantage of this index is that it extracts information from different frequencies. To the best of our knowledge, there are many studies that have focused on methodologies for generating IV forecasts. However, most of them have studied VIX, ${ }^{2}$ the most representative IV index for the U.S. stock markets. In this case, we examine whether the forecasting ability of OVX, as a measure for crude oil volatility, can be improved by incorporating other IV indicators and factors of uncertainty within a simple methodological framework. The number of studies that have aimed to produce OVX forecasts is limited, and none of them has investigated the predictive information of all these factors of uncertainty on OVX, which is the main contribution of this paper. In order to evaluate the OVX forecasts, we implement two statistical loss functions, namely the Mean Squared Predictive Error (MSPE) and the Mean Absolute Error (MAE). Moreover, to enhance the evaluation framework, we apply the Model Confidence Set (MCS) test. The results reveal that the individual model that incorporates the EPU index outperforms the remaining models in an out-of-sample investigation. However, it is noted that the model that includes all exogenous variables does not outperform the simple Autoregressive Distributed Lag (ADL) model when referring to out-of-sample results compared to its performance on the in-sample analysis. The remainder of the paper is structured as follows. In Section 2 we provide a review of the literature on the relationship between OVX and the exogenous factors representing uncertainty. In Section 3 we describe the data used in the study. In Section 4 we present the methodological framework implemented and the way the OVX forecasts are generated. The evaluation framework used for the obtained forecasts is presented in Section 5, while in Section 6 we discuss the in-sample and out-of-sample results. Finally, Section 7 concludes the study.

\section{OVX and Uncertainty}

\subsection{Relationship between OVX and Other IV Indices}

The relationship between the crude oil market and other markets, such as the stock and foreign exchange, has been thoroughly investigated in recent years. Several papers have focused on the interconnectedness between crude oil and other assets, with the majority of them emphasizing returns. For example, Filis and Chatziantoniou (2014) concentrated on the relationship between crude oil returns and aggregated stock market indices in a Vector Autoregression (VAR) model. Moreover, Filis, Degiannakis, and Floros (2011) and Degiannakis, Filis, and Floros (2013) investigated the time-varying relationship between oil and stock markets by using multivariate GARCH models. However, because the volatility of crude oil prices is considered important to oil investors and policy makers, researchers have studied the relationship between these markets at a volatility level. Liu, Ji, and Fan (2013) focused on the relationship between OVX and other IV indices and concluded that there is transmission from the stock market to the crude oil market, which they characterize as short-lived. However, the methodological framework of this study was limited to in-sample analysis. In an out-of-sample investigation, Chatziantoniou, Degiannakis, Delis, and Filis (2021) considered spillovers between OVX and other uncertainty indicators, such as the VIX, and found that spillovers do not contain significant predictive information, which is something that the current paper studies

${ }^{1}$ For further details, see: https://cdn.cboe.com/api/global/us_indices/governance/VIX_Methodology.pdf.

${ }^{2}$ For example, see Degiannakis (2008) and Fernandes, Medeiros, and Scharth (2014). 
in depth. More specifically, we generate out-of-sample forecasts of OVX by incorporating three core IV indices, namely the VIX, the CBOE Gold ETF Volatility index (GVZ) and the CBOE/CBOT 10-year U.S. Treasury Note Volatility (TYVIX).

\subsection{Relationship between OVX and Other Uncertainty Factors}

Aside from the studies that examine the relationship between OVX and other IV indices, a limited number of papers has focused on the relationship between OVX and certain indicators of uncertainty, such as that of Chatziantoniou et al. (2021). In their study, indicators such as the economic policy uncertainty index, the partisan conflict index and the geopolitical risk index were examined for their predictive power when using their spillovers with the OVX. Moreover, Dutta, Bouri, and Saeed (2021) investigated the impact of news-based equity market volatility trackers on crude oil volatility. They found that several trackers provide better forecasting power than the VIX, EPU and GPR indices.

\section{Data Description}

The target variable of this study is the IV of crude oil, namely the OVX. CBOE constructed the OVX time series using the same methodology that produced the other IV time series. According to this methodology, in the case of VIX, the index is calculated using the midpoint of real-time S\&P 500 index (SPX) option bid/ask quotes. More specifically, according to CBOE, the VIX index provides a measure of how much the market expects the S\&P 500 index to fluctuate in the 30 days from the time of each tick of the VIX index. The examined determinants of OVX that are included in the modelling framework are the following IV indices: VIX, GVZ and TYVIX. The VIX index, as mentioned above, is a calculation designed to produce a measure of constant, 30-day expected volatility of the U.S. stock market. The GVZ is an estimate of the expected 30-day volatility of returns on the SPDR Gold Shares ETF and the TYVIX is the implied volatility index representing the macroeconomic conditions. We use daily data from the $18^{\text {th }}$ of September 2009 up to the $1^{\text {st }}$ of October 2019 for the four IV indices (i.e. 2523 observations). All are extracted from the CBOE website. Regarding the other factors of uncertainty that are examined for their predictive information on OVX, we use daily data for the same period defined in the previous paragraph. The U.S. economic policy uncertainty index is based on newspaper archives that contain thousands of newspapers and other news sources. More particularly, for the calculation of this measure, the news sources are restricted to the United States. ${ }^{3}$ Regarding the geopolitical risk factor, which is calculated by counting the number of articles related to adverse geopolitical events, the data is retrieved from the website of Caldara and Iacoviello." Finally, the last factor of uncertainty we use is the Aruoba-Diebold-Scotti (ADS) business conditions index, which is designed to track real business conditions by taking into account data of macroeconomic variables at different frequencies. A major advantage of this index is the fact that at the time of any ADS update, the index is based on all information of all indicators available at that time. ${ }^{5}$ Table 1 provides a summary of the descriptive statistics for all variables, including the uncertainty factors used in this study. We first observe that the mean of OVX is higher than the means of the other IV indices. However, the coefficient of variation of VIX is higher than those of OVX and the other IV indices. Figure 1 and Figure 2 illustrate the evolution of the IV indices and the other indicators that represent uncertainty.

Table 1. Descriptive statistics.

\begin{tabular}{l|c|c|c|c|c|c|c}
\hline & OVX & VIX & GVZ & TYVIX & EPU & GPR & ADS \\
\hline Mean & 33.42 & 17.12 & 17.32 & 5.51 & 104.27 & 103.62 & -0.10 \\
\hline Median & 32.10 & 15.73 & 16.83 & 5.30 & 89.80 & 97.22 & -0.10 \\
\hline Minimum & 14.50 & 9.14 & 8.88 & 3.16 & 3.32 & 9.48 & -0.81 \\
\hline Maximum & 78.97 & 48.00 & 39.95 & 10.33 & 490.89 & 361.02 & 0.88 \\
\hline Std. Dev. & 10.18 & 5.71 & 4.93 & 1.32 & 60.01 & 38.29 & 0.32 \\
\hline Skewness & 0.79 & 1.61 & 0.86 & 0.68 & 1.59 & 1.22 & 0.34 \\
\hline Kurtosis & 3.78 & 6.35 & 4.17 & 2.85 & 6.88 & 5.84 & 3.01 \\
\hline Coefficient of Variation & 0.30 & 0.33 & 0.28 & 0.24 & 0.58 & 0.37 & -3.20 \\
\hline
\end{tabular}

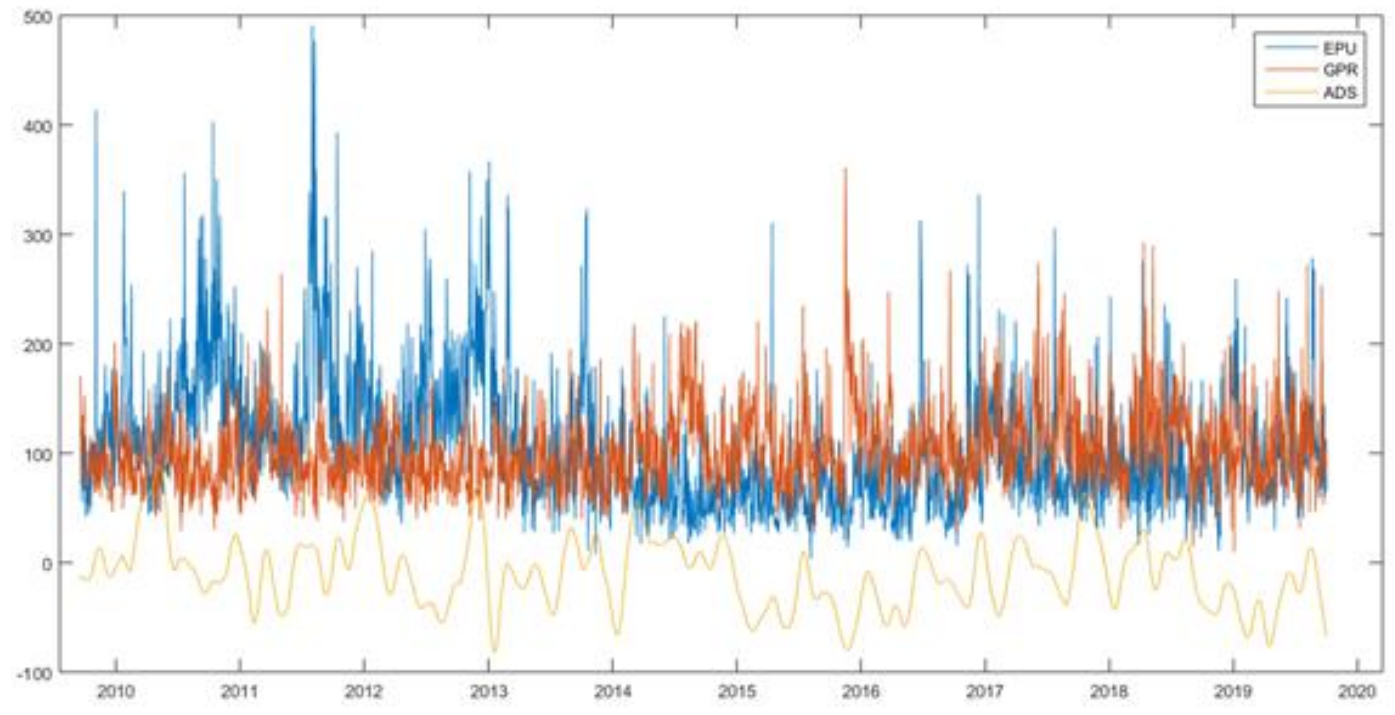

Figure 1. All implied volatility indices, namely the OVX, VIX, GVZ and TYVIX, over time.

\footnotetext{
${ }^{3}$ The data is extracted from the relevant website: https://www.policyuncertainty.com/us_monthly.html.

${ }^{4}$ For further details see the link: https://www.matteoiacoviello.com/gpr.htm.

${ }_{5}$ The data is extracted from the website: https://www.philadelphiafed.org/surveys-and-data/real-time-data-research/ads.
} 


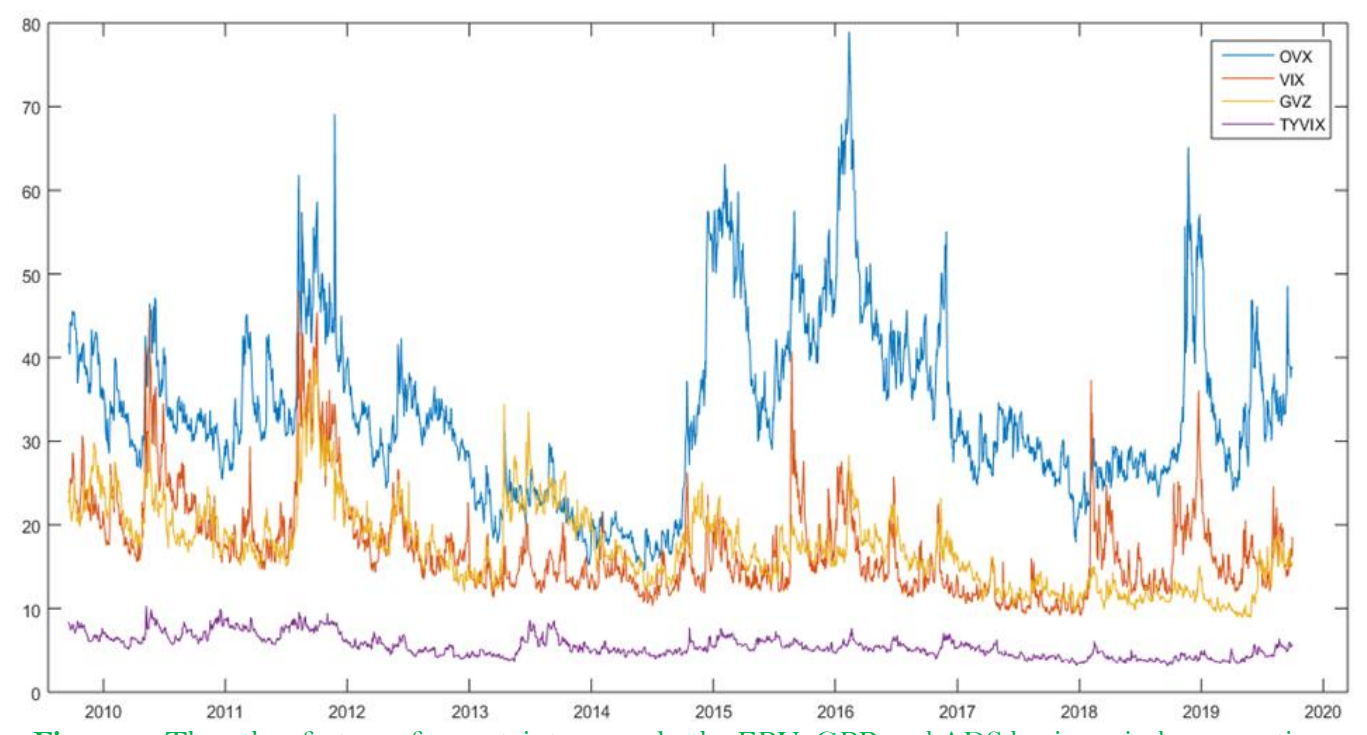

Figure 2. The other factors of uncertainty, namely the EPU, GPR and ADS business index, over time.

\section{Methodology}

\subsection{Nä̈ve Models}

The simplest model we use for comparison purposes is an ADL model, which is specified as follows:

$$
\log \left(O V X_{t}\right)=a_{0}^{(t)}+a_{1}^{(t)} \log \left(O V X_{t-1}\right)+\varepsilon_{t},
$$

where $a_{0}^{(t)}, a_{1}^{(t)}$ are the rolling estimated coefficients and $\varepsilon_{t}$ denotes the white noise.

\subsection{Models with Exogenous Information}

One of the main contributions of this study, though, is the fact that we investigate the predictive information that uncertainty factors from different categories might offer when generating OVX forecasts. In order to compare the forecasting ability of these exogenous variables to the OVX, we use the specification of the above ADL model and add the uncertainty factors as exogenous variables in each model. Therefore, each individual model that incorporates exogenous variables can be written as follows:

$$
\log \left(O V X_{t}\right)=a_{0}^{(t)}+a_{1}^{(t)} \log \left(O V X_{t-1}\right)+b^{(t)} E X_{t-1}^{(i)}+\varepsilon_{t}
$$

where $a_{0}^{(t)}, a_{1}^{(t)}, b^{(t)}$ are the rolling estimated coefficients, and $E X_{t-1}^{(i)}$ is the one-lagged exogenous variable $i$, which represents the uncertainty indicator that is different in each individual model. However, it is also important to study the information that all the exogenous variables offer in a model and see whether the predictive ability of this model is improved in comparison with the individual models. Therefore, we further introduce a model with all exogenous variables added, which is written as follows:

$$
\log \left(O V X_{t}\right)=a_{0}^{(t)}+a_{1}^{(t)} \log \left(O V X_{t-1}\right)+\sum_{i=1}^{M} b_{i}^{(t)} E X_{t-1}^{(i)}+\varepsilon_{t}
$$

where $M$ is the total number of factors representing uncertainty, including the implied volatility indices and the other uncertainty indicators, such as the economic policy uncertainty index.

\subsection{How are the OVX Forecasts Obtained/Produced?}

The total number of days used in this study is 2522. The out-of-sample forecasting period consists of 1522 days, and we use 1000 days as an initial sample period. The choice of the initial sample period is based on the number of days used by the majority of prior studies, which can be justified by the fact that a large sample size is considered crucial for the estimation of the implemented models. Moreover, it is important to note that the starting date of the out-of-sample forecasting period is September 11,2013, which means that the period of the oil collapse between 2014 and 2016 is included in the sample. This is of major significance to this study because it gives us the ability to evaluate the forecasting performance of the models in this particularly volatile period and not only in more tranquil periods. In this paper, 1-day ahead OVX forecasts are generated based on a rolling window approach with a fixed window length of 1000 daily observations. The equation that shows how these OVX forecasts are generated from a model with a single exogenous variable is the following:

$$
O V X_{t+1 \mid t}=\exp \left(a_{0}^{(t)}+a_{1}^{(t)} \log \left(O V X_{t}\right)+b^{(t)} E X_{t}^{(i)}\right) .
$$

\section{Evaluation Framework}

\subsection{Statistical Loss Functions}

Having obtained the 1-day ahead forecasts of OVX, we evaluate the predictive performance of the applied models in generating these forecasts. Two well-known statistical loss functions, namely the Mean Squared Predictive Error (MSPE) and the Mean Absolute Error (MAE), have been used to compare the forecasting ability of the implemented models. Specifically, these two loss functions are computed as follows:

$$
M S P E=\frac{1}{T_{1}} \sum_{t=1}^{T_{1}}\left(O V X_{t+1 \mid t}-O V X_{t+1}\right)^{2}
$$




$$
M A E=\frac{1}{T_{1}} \sum_{t=1}^{T_{1}}\left|O V X_{t+1 \mid t}-O V X_{t+1}\right|,
$$

where $T_{1}$ is the number of out-of-sample forecasting days $\left(T_{1}=1522\right)$.

\subsection{Model Confidence Set}

In addition to the abovementioned statistical loss functions, we aim to determine the set of models that are the best in terms of forecasting performance under the two loss functions. Therefore, we use the MCS test proposed by Hansen, Lunde, and Nason (2011) to further evaluate our OVX forecasts. This specific framework investigates the set of models that remains until the end in an elimination algorithm at a level of significance $a$. To start the process, we define the full set of models $M=M_{0}=\left\{1, \ldots, m_{0}\right\}$, and the following null hypothesis of equal predictive ability is repeatedly tested:

Against this alternative one:

$$
H_{0, M}: E\left(d_{j, j^{*}, t}\right)=0 \text {, for } \forall j, j^{*} \in M,
$$

$$
H_{1, M}: E\left(d_{j, j^{*}, t}\right) \neq 0 \text {. }
$$

for some $j, j^{*} \in M$. The $d_{j, j^{*}, t}$ is defined as $d_{j, j^{*}, t}=L F_{j, t}-L F_{j^{*}, t}$ with $L F_{j, t}$ to be denoted either as $L F_{j, t}=\left(O V X_{t+1 \mid t}-O V X_{t+1}\right)^{2}$ or as $L F_{j, t}=\left|O V X_{t+1 \mid t}-O V X_{t+1}\right|$, where $O V X_{t+1 \mid t}$ is the 1-day ahead forecast of OVX generated by the $j^{t h}$ model. Therefore, this procedure is repeated until the null hypothesis is no longer rejected. Regarding the characteristics of the MCS test, we predefine the level of significance $a=0.1$ and the number of bootstrap replications is 10,000 .

\section{Results}

First, it is important to note the relationship between the dependent variable, the OVX, and the explanatory variables considered in this study. As shown in Figure 3, the relationship between OVX and the other uncertainty indicators does not seem to be linear. Moreover, the correlation between OVX and the explanatory variables is not higher than $51 \%$, which is the case for VIX.
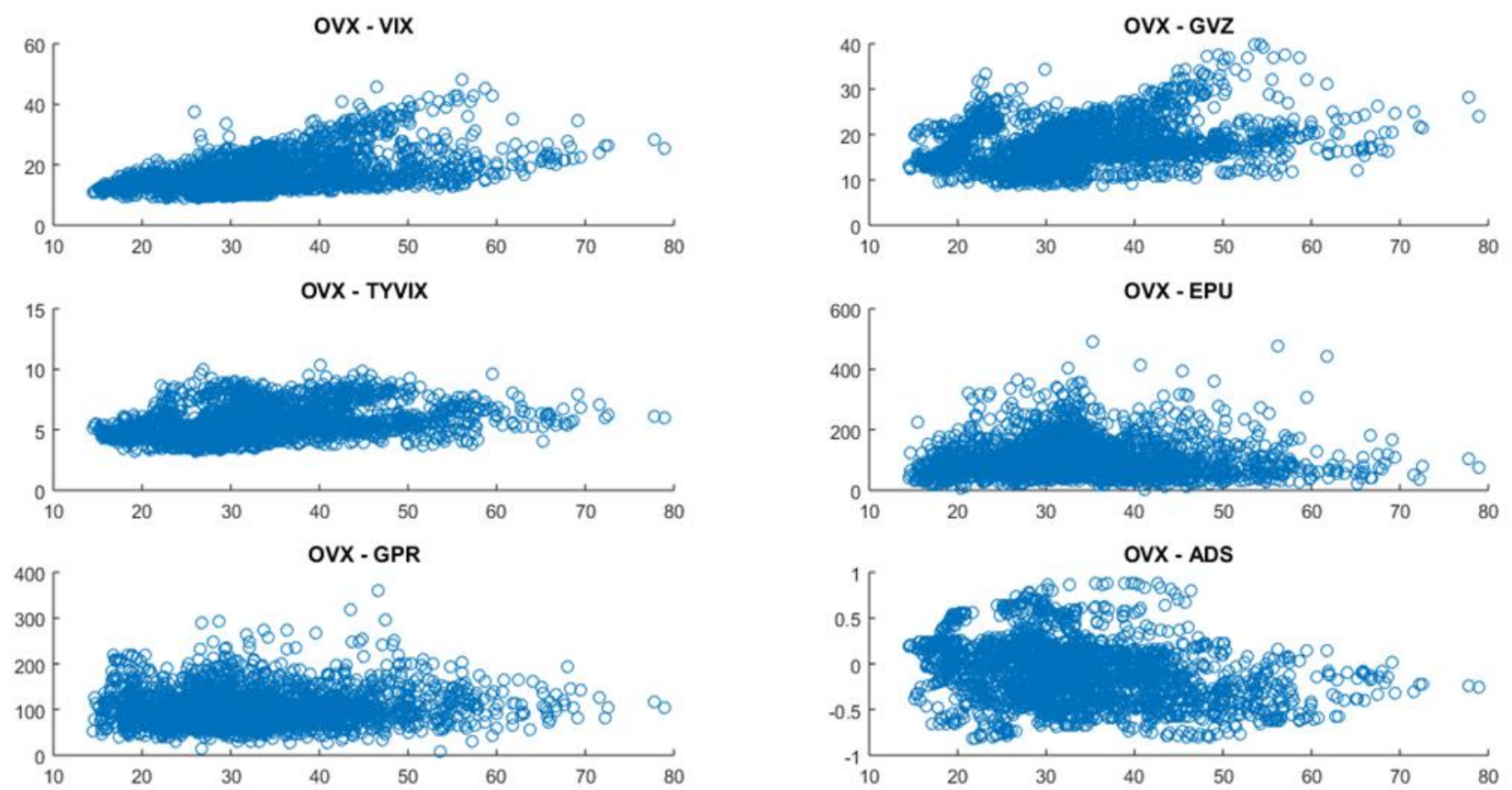

Figure 3. Scatter plots between OVX and each of the uncertainty indicators used as explanatory variables in the modeling framework.

In addition, Table 2 shows that OVX is not correlated with EPU or GPR and is negatively correlated with the ADS business index.

Table 2. Correlation matrix.

\begin{tabular}{l|l|l|l|l|l|l|l}
\hline & OVX & VIX & GVZ & TYVIX & EPU & GPR & ADS \\
\hline OVX & 1.00 & 0.51 & 0.32 & 0.34 & 0.03 & 0.04 & -0.27 \\
\hline VIX & 0.51 & 1.00 & 0.63 & 0.57 & 0.34 & -0.12 & 0.10 \\
\hline GVZ & 0.32 & 0.63 & 1.00 & 0.68 & 0.23 & -0.17 & 0.13 \\
\hline TYVIX & 0.34 & 0.57 & 0.68 & 1.00 & 0.27 & -0.12 & 0.13 \\
\hline EPU & 0.03 & 0.34 & 0.23 & 0.27 & 1.00 & -0.14 & 0.12 \\
\hline GPR & 0.04 & -0.12 & -0.17 & -0.12 & -0.14 & 1.00 & -0.02 \\
\hline ADS & -0.27 & 0.10 & 0.13 & 0.13 & 0.12 & -0.02 & 1.00 \\
\hline
\end{tabular}




\begin{tabular}{|c|c|c|c|c|c|c|c|c|}
\hline & & \multicolumn{6}{|c|}{ Individual model } & \multirow[b]{2}{*}{ All-Variables } \\
\hline & ADL & VIX & GVZ & TYVIX & EPU & GPR & ADS & \\
\hline \multirow[t]{2}{*}{ Intercept } & $0.04485 * * *$ & $0.04099^{* * * * *}$ & $0.04643^{*} * * *$ & $0.04350^{* * * * *}$ & $0.04636^{* * * * *}$ & $0.04871 * * *$ & $0.04800^{* * * * *}$ & $0.05468^{* * * * *}$ \\
\hline & $(-0.01108)$ & $(0.01178)$ & $(0.01296)$ & $(0.01151)$ & $(0.01112)$ & $(0.01133)$ & $(0.01140)$ & $(0.01372)$ \\
\hline \multirow[t]{2}{*}{$\log (\mathrm{OVX})$ - 1 lag } & $0.98704 * * * *$ & $0.98519^{* * * *}$ & $0.98728^{* * * *}$ & $0.98651 * * *$ & $0.98739 * * * *$ & $0.98716^{* * * *}$ & $0.98603^{* * * *}$ & $0.98247 * * * *$ \\
\hline & $(0.00319)$ & $(0.00372)$ & $(0.00335)$ & $(0.00342)$ & $(0.00319)$ & $(0.00319)$ & $(0.00330)$ & $(0.00406)$ \\
\hline \multirow[t]{2}{*}{$\log (\mathrm{VIX})-1$ lag } & & 0.00368 & & & & & & $0.00865^{*}$ \\
\hline & & $(0.00379)$ & & & & & & $(0.00478)$ \\
\hline \multirow[t]{2}{*}{$\log (G V Z)-1$ lag } & & & -0.00085 & & & & & -0.00710 \\
\hline & & & $(0.00364)$ & & & & & $(0.00538)$ \\
\hline \multirow[t]{2}{*}{$\log ($ TYVIX $)$ - 1 lag } & & & & 0.00192 & & & & 0.00606 \\
\hline & & & & $(0.00441)$ & & & & $(0.00627)$ \\
\hline \multirow[t]{2}{*}{ EPU - 1 lag } & & & & & -0.00003 & & & $-0.00004 * *$ \\
\hline & & & & & $(0.00002)$ & & & $(0.00002)$ \\
\hline \multirow[t]{2}{*}{ GPR - 1 lag } & & & & & & $-0.00004^{*}$ & & $-0.00005^{*}$ \\
\hline & & & & & & $(0.00003)$ & & $(0.00003)$ \\
\hline \multirow[t]{2}{*}{ ADS - 1 lag } & & & & & & & -0.00372 & -0.00420 \\
\hline & & & & & & & $(0.00313)$ & $(0.00327)$ \\
\hline $\mathrm{R}^{\wedge} 2$ & 0.97439 & 0.97440 & 0.97439 & 0.97439 & 0.97442 & 0.97442 & 0.97441 & 0.97451 \\
\hline Adjusted $\mathrm{R}^{\wedge} 2$ & 0.97438 & 0.97438 & 0.97437 & 0.97437 & 0.97440 & 0.97440 & 0.97439 & 0.97444 \\
\hline LL & 4066.85090 & 4067.32246 & 4066.87857 & 4066.94522 & 4068.15174 & 4068.20648 & 4067.55525 & 4072.73837 \\
\hline AIC & -8129.70181 & -8128.64492 & -8127.75714 & -8127.89044 & -8130.30348 & -8130.41296 & -8129.11049 & -8129.47674 \\
\hline $\mathrm{BIC}$ & -8118.03619 & -8111.14649 & -8110.25872 & -8110.39202 & -8112.80505 & -8112.91454 & -8111.61207 & -8082.81428 \\
\hline
\end{tabular}

Note: Results of the estimations for all models implemented in the empirical

null hypothesis of a zero coefficient at the $1 \%, 5 \%$ and $10 \%$ level, respectively. 
Table 4. Out-of-sample results.

\begin{tabular}{c|c|c|c|c}
\hline & MSPE & MCS (squared errors) & MAE & MCS (absolute errors) \\
\hline RW & 3.379 & 0.705 & 1.204 & 0.819 \\
\hline ADL & 3.367 & 0.705 & 1.203 & 0.768 \\
\hline Model - VIX & 3.375 & 0.540 & 1.209 & 0.050 \\
\hline Model - GVZ & 3.378 & 0.540 & 1.201 & 0.875 \\
\hline Model - TYVIX & 3.380 & 0.256 & 1.205 & 0.324 \\
\hline Model - EPU & 3.361 & 1.000 & 1.201 & 1.000 \\
\hline Model - GPR & 3.361 & 0.974 & 1.203 & 0.819 \\
\hline Model - ADS & 3.366 & 0.705 & 1.204 & 0.745 \\
\hline Model - ALL & 3.373 & 0.705 & 1.206 & 0.324 \\
\hline
\end{tabular}

Regarding the models applied in this study, the results for the corresponding coefficients are shown in Table 3. It is obvious that the one-lagged variable of OVX is always statistically significant at $1 \%$. Moreover, we can see that only GPR is statistically significant at $10 \%$, when referring to the individual models. However, when we include all exogenous variables in the model, not only the coefficient of GPR but also those of EPU and VIX are statistically significant, which provides a clue to the potential predicting information these uncertainty indicators offer on OVX. Moreover, this model presents the highest $R^{2}$ in comparison with the other models.

In this study, we assess several indicators' ability to predict OVX, focusing on an out-of-sample investigation, as extensively described in Section 4.3. After generating the 1-day ahead forecasts of OVX, we evaluate the forecasting performance of the implemented models, using two statistical loss functions and the MCS test. According to Table 4, in terms of MSPE, the individual models that include EPU and GPR as exogenous variables are the two models that display a better performance compared to the remaining ones. When referring to the results of the MAE statistical loss function, we see that the model that includes EPU is again one of the best models, together with the model that has GVZ as the exogenous variable. Therefore, we can draw the conclusion that the individual model that includes EPU outperforms the competing models, which can be justified by the results of the MCS test, which show that it is always included in the set of best models. It is worth noting that even if the model that includes all variables performs well in an in-sample analysis, it is inferior to several individual models in an out-of-sample investigation and cannot be considered adequate for generating OVX forecasts. Even the simple ADL model performs better than the model that includes all the uncertainty indicators from both categories, namely the implied volatility indices and the other factors of uncertainty representing geopolitical, economic and business conditions.

\section{Conclusion}

This paper aimed to find whether uncertainty indicators can offer predictive information on OVX and, if so, which indicators. We defined two groups of indicators representing uncertainty. The first group consisted of implied volatility indices, namely the VIX, GVZ and TYVIX indices. The indicators in the second group represented economic, business and geopolitical risks; these were investigated afterwards.

In the in-sample analysis, we observed that the model that included all indicators as exogenous variables could be considered the best one, with the highest coefficient of determination. However, the good performance of this model was not maintained in the out-of-sample investigation, in which it was even outperformed by an ADL model that included only the first lag of the OVX. Regarding the out-of-sample results and, more specifically, the results of the two statistical loss functions, the individual model that incorporated the EPU indicator outperformed the remaining models for both the MSPE and MAE loss functions.

The results of this paper might be considered inspiring for both academics and investors and give ideas for further research. One extension of this paper could be in the evaluation framework, which could be enhanced by implementing some trading strategies in order to discover whether the indicators included in the models could offer forecasting gains.

\section{References}

Blair, B. J., Poon, S. H., \& Taylor, S. J. (2001). Forecasting S\&P 100 volatility: The incremental information content of implied volatilities and high-frequency index returns. Journal of Econometrics, 105(1), 5-26.Available at: https://doi.org/10.1016/s0304-4076(01)00068-9.

Chatziantoniou, I., Degiannakis, S., Delis, P., \& Filis, G. (2021). Forecasting oil price volatility using spillover effects from uncertainty indices. Finance Research Letters, 42, 101885.Available at: https://doi.org/10.1016/j.frl.2020.101885.

Degiannakis, S., Filis, G., \& Floros, C. (2013). Oil and stock returns: Evidence from European industrial sector indices in a time-varying environment. Journal of International Financial Markets, Institutions and Money, 26, 175-191.Available at: https://doi.org/10.1016/j.intfin.2013.05.007.

Degiannakis, S., Filis, G., \& Hassani, H. (2018). Forecasting global stock market implied volatility indices. Journal of Empirical Finance, 46, 111-129.Available at: https://doi.org/10.1016/j.jempfin.2017.12.008.

Degiannakis., S. (2008). Forecasting Vix. Germany: University Library of Munich.

Dunis, C., Kellard, N. M., \& Snaith, S. (2013). Forecasting EUR-USD implied volatility: The case of intraday data. Journal of Banking \& Finance, 37(12), 4943-4957.Available at: https://doi.org/10.1016/j.jbankfin.2013.08.028.

Dutta, A., Bouri, E., \& Saeed, T. (2021). News-based equity market uncertainty and crude oil volatility. Energy, 222, 119930.Available at: https://doi.org/10.1016/j.energy.2021.119930.

Fernandes, M., Medeiros, M. C., \& Scharth, M. (2014). Modeling and predicting the CBOE market volatility index. Journal of Banking \& Finance, 40, 1-10.Available at: https://doi.org/10.1016/j.jbankfin.2013.11.004.

Filis, G., \& Chatziantoniou, I. (2014). Financial and monetary policy responses to oil price shocks: Evidence from oil-importing and oilexporting countries. Review of Quantitative Finance and Accounting, 42(4), 709-729.Available at: https://doi.org/10.1007/s $11156-013-$ 0359-7.

Filis, G., Degiannakis, S., \& Floros, C. (2011). Dynamic correlation between stock market and oil prices: The case of oil-importing and oilexporting countries. International Review of Financial Analysis, 2O(3), 152-164.Available at: https://doi.org/10.1016/j.irfa.2011.02.014.

Frijns, B., Tallau, C., \& Tourani-Rad, A. (2010). The information content of implied volatility: Evidence from Australia. Journal of Futures Markets: Futures, Options, and Other Derivative Products, 30(2), 134-155.

Giot, P. (2003). The information content of implied volatility in agricultural commodity markets. Journal of Futures Markets: Futures, Options, and Other Derivative Products, 23(5), 441-454.Available at: https://doi.org/10.1002/fut.10069. 
Hansen, P. R., Lunde, A., \& Nason, J. M. (2011). The model confidence set. Econometrica, 79(2), 453-497.Available at: https://doi.org/10.3982/ecta5771.

Konstantinidi, E., Skiadopoulos, G., \& Tzagkaraki, E. (2008). Can the evolution of implied volatility be forecasted? Evidence from European and US implied volatility indices. Journal of Banking \& Finance, 32(11), 2401-2411.Available at: https://doi.org/10.1016/j.jbankfin.2008.02.003.

Liu, M.-L., Ji, Q., \& Fan, Y. (2013). How does oil market uncertainty interact with other markets? An empirical analysis of implied volatility index. Energy, 55, 860-868.Available at: https://doi.org/10.1016/j.energy.2013.04.037.

Mazzeu, J. H. G., Veiga, H., \& Mariti, M. B. (2019). Modeling and forecasting the oil volatility index. Journal of Forecasting, 38(8), 773787.Available at: https://doi.org/10.1002/for.2598. 